\title{
Effect of Rotor Angle Displacement on Synchronous Generator Transient Condition under Three-phase Fault
}

\author{
Thu Zar Mon \\ Department of Electrical Power Engineering, \\ Mandalay Technological University, \\ Mandalay, Myanmar
}

\author{
Yan Aung Oo \\ Department of Electrical Power Engineering, \\ Mandalay Technological University, \\ Mandalay, Myanmar
}

\begin{abstract}
This paper approaches the effect of change of rotor angle upon armature current due to short circuit condition at the terminal of the synchronous generator. The synchronous machine as an AC generator, driven by the turbine to convert mechanical energy to electrical energy, is the major electric power-generating source throughout the world. The severest condition of three-phase shortcircuit waveform is naturally higher than the steady-state condition concerning with AC component of armature current, because armature reactances change due to armature reaction. The Park's equations are solved numerically during balanced three-phase shortcircuit. Under three-phase fault is applied at the terminal of the synchronous generator, the fault current waveforms of $i_{a}, i_{b}, i_{c}$ and $i_{F}$ are observed for the various rotor angle displacements, i.e, $\delta=0^{\circ}, \delta=30^{\circ}, \delta=60^{\circ}$ and $\delta=90^{\circ}$. The transformed quantities are obtained from the projection of the actual variable on three axis; one along the direct axis, a second along the quadrature axis, and the third on a stationary axis. The interest is to study the wave form of the currents of the armature and field windings under three-phase short-circuit at the terminal of synchronous machine by using the MATLAB program.
\end{abstract}

Keywords: Park transformation, rotor angle, symmetrical fault, synchronous machine, transient

\section{INTRODUCTION}

In large interconnected power system, the synchronous machine includes as a main part in the application and operation of electric supply. The synchronous machine as an ac generator, driven by the turbine to convert mechanical energy to electrical energy, is the major electric powergenerating source throughout the world [1].In this paper, the resulting differential equations describing the synchronous machine's characteristic due to the short circuit condition of three phase fault. These nonlinear equations are transformed into linear differential equations using Park's transformation. MATLAB is used with ease to simulate the nonlinear differential equations [2]. The events within a generator subjected to a sudden short-circuit depend on several factors; including (i) the instant in the cycle at which short-circuit is initiated (ii) the load and excitation of the machine at this time.

\section{PROBLEM STATEMENT}

Under transient conditions, such as short circuits at generator terminal, the flux linkages with the rotor circuits change with time. This result of transient currents in all rotor circuits reacts on armature [3].For the transient analysis, the idealized synchronous machine is represented as a group of magnetically coupled circuits with inductances, which depend on angular position of the rotor. The resulting differential equations describing the machine have time varying coefficients, and a closed form of solution in most cases is not feasible.

\section{SYNCHRONOUS MACHINE TRASIENT}

The synchronous machine consists of three stator windings mounted on the stator, and one field winding mounted on the rotor. Two additional fictitious windings could be added to the rotor, one along the direct axis and one along the quadrature axis, which model the short-circuited paths of the damper windings. These windings are shown schematically in Figure 1 .

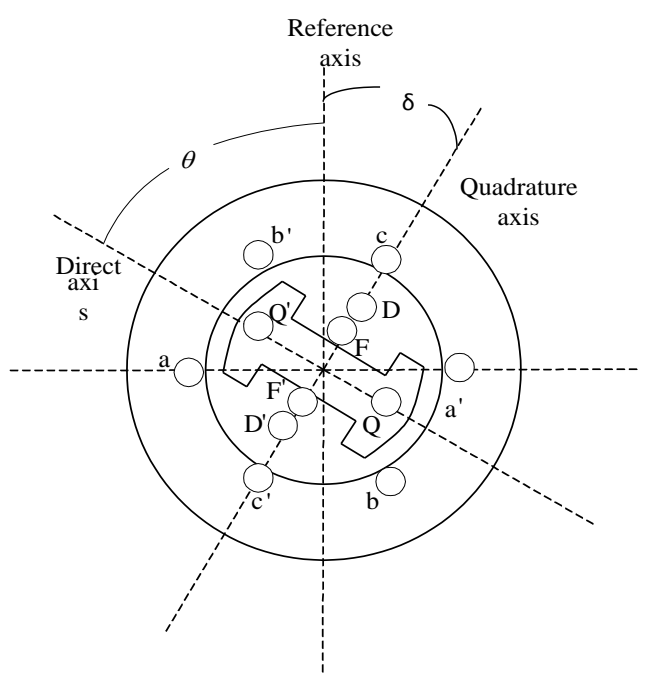

Figure 1. Schematic representation of a synchronous machine

Assuming a synchronously rotating reference frame (axis) is rotating with the synchronous speed $\omega$ which will be along the axis of phase $a$ at $t=0$. If $\theta$ is the angle by which rotor direct axis is ahead of the magnetic axis of phase $a$, then

$\theta=\omega t+\delta+\pi / 2$

Where, $\delta$ is the displacement of the quadrature axis from the synchronously rotating reference axis and $(\delta+\pi / 2)$ is the displacement of the direct axis.

In the classical method, the idealized synchronous machine is represented as a group of magnetically coupled circuits with inductances, which depend on the angular position of the rotor. In addition, saturation is neglected and spatial distribution of armature mmf is assumed sinusoidal [4].

\section{PARK TRANSFORMATION}

Park Transformation is a well-known technique in the analysis of electric machines, where the three rotating phases abc are transferred to three equivalent stationary $\mathrm{dq} 0$ phases $(\mathrm{d}-\mathrm{q}$ 
reference frame). A great simplification can be made by transformation of stator variables from phases $a, b$, and $c$ into new variables the frame of reference of which moves with the rotor. The transformation is based on the so-called two-axis theory [5].

The transformed quantities are obtained from the projection of the actual variables on three axes; one along the direct axis of the rotor field winding, called the direct axis; a second along the neutral axis of the field winding, called the quadrature axis; and the third on a stationary axis. The three armature currents $i_{a}, i_{b}$, and $i_{c}$ are replaced by three fictitious currents with the symbols $i_{d}, i_{q}$, and $i_{0}$. They are found such that, in a balanced condition, when $i_{a}+i_{b}+i_{c}=0$, they produce the same flux, at any instant, as the actual phase currents in the armature. The third fictitious current $i_{0}$ is needed to make the transformation possible when the sum of the three-phase current is not zero [6].

The Park transformation for currents is as follows

$\left[\begin{array}{c}\mathrm{i}_{0} \\ \mathrm{i}_{\mathrm{d}} \\ \mathrm{i}_{\mathrm{q}}\end{array}\right]=\sqrt{2} / 3\left[\begin{array}{ccc}1 / \sqrt{2} & 1 / \sqrt{2} & 1 / \sqrt{2} \\ \cos \theta & \cos (\theta-2 \pi / 3) & \cos (\theta+2 \pi / 3) \\ \sin \theta & \sin (\theta-2 \pi / 3) & \sin (\theta+2 \pi / 3)\end{array}\right]\left[\begin{array}{l}\mathrm{i}_{\mathrm{a}} \\ \mathrm{i}_{\mathrm{b}} \\ \mathrm{i}_{\mathrm{c}}\end{array}\right]$

or, in matrix notation

$i_{\text {Odq }}=\mathrm{P} i_{a b c}$

Similarly for voltages and flux linkages,

$v_{O d q}=\mathrm{P} v_{a b c}$

$\lambda_{O D Q}=\mathrm{P} \lambda_{A B C}$

$\mathrm{P}$ matrix is augmented with a $3 \times 3$ identity matrix $\mathrm{U}$ (unit matrix) to get;

$\left[\begin{array}{c}\lambda_{0 d q} \\ \lambda_{F D Q}\end{array}\right]=\left[\begin{array}{cc}P & 0 \\ 0 & U\end{array}\right]\left[\begin{array}{c}\lambda_{a b c} \\ \lambda_{F D Q}\end{array}\right]$

or $\left[\begin{array}{c}\lambda_{a b c} \\ \lambda_{F D Q}\end{array}\right]=\left[\begin{array}{cc}P^{-1} & 0 \\ 0 & U\end{array}\right]\left[\begin{array}{c}\lambda_{0 d q} \\ \lambda_{F D Q}\end{array}\right]$

Transforming the stator-based currents $\left(i_{a b c}\right)$ into rotor-based currents $\left(i_{0 d q}\right)$, with rotor currents unaffected,

$\left[\begin{array}{c}i_{a b c} \\ { }^{i} F D Q\end{array}\right]=\left[\begin{array}{cc}P^{-1} & 0 \\ 0 & U\end{array}\right]\left[\begin{array}{c}i_{0 d q} \\ i_{F D Q}\end{array}\right]$

or $\left[\begin{array}{c}i_{a b c} \\ i_{F D Q}\end{array}\right]=\left[\begin{array}{cc}P^{-1} & 0 \\ 0 & U\end{array}\right]\left[\begin{array}{c}i_{0 d q} \\ i_{F D Q}\end{array}\right]$

Once a solution is obtained for the direct axis and quadrature axis currents, the phase currents are obtained through the inverse Park transformation.

$\mathrm{i}_{\mathrm{abc}}=\mathrm{P}^{-1} \mathrm{i}_{0 \mathrm{dq}}$

Substituting for $P^{-1}$ from (4), and noting $i_{0}=0$, the phase currents are

$\mathrm{i}_{\mathrm{a}}=\mathrm{i}_{\mathrm{d}} \cos \theta+\mathrm{i}_{\mathrm{q}} \sin \theta$

$i_{b}=i_{d} \cos (\theta-2 \pi / 3)+i_{q} \sin (\theta-2 \pi / 3)$

$i_{c}=i_{d} \cos (\theta+2 \pi / 3)+i_{q} \sin (\theta+2 \pi / 3)$

\section{PROGRAM APPLICATION}

\section{PACKAGE}

The flow chart for three-symmetrical short-circuits and "symshort" function diagrams are as shown in Figure 2 and Figure 3 .

The software package is an environment for power system analysis running under the Microsoft Windows platform operating system MATLAB is the programming language contributing to the current development of the software package. The software environment is conceptually structured in the form of a tree.

The purpose of this tree structure is to facilitate the future extension of the package and accessibility of all the modules of the environment and at the same time assist the user in choosing the correct next module.

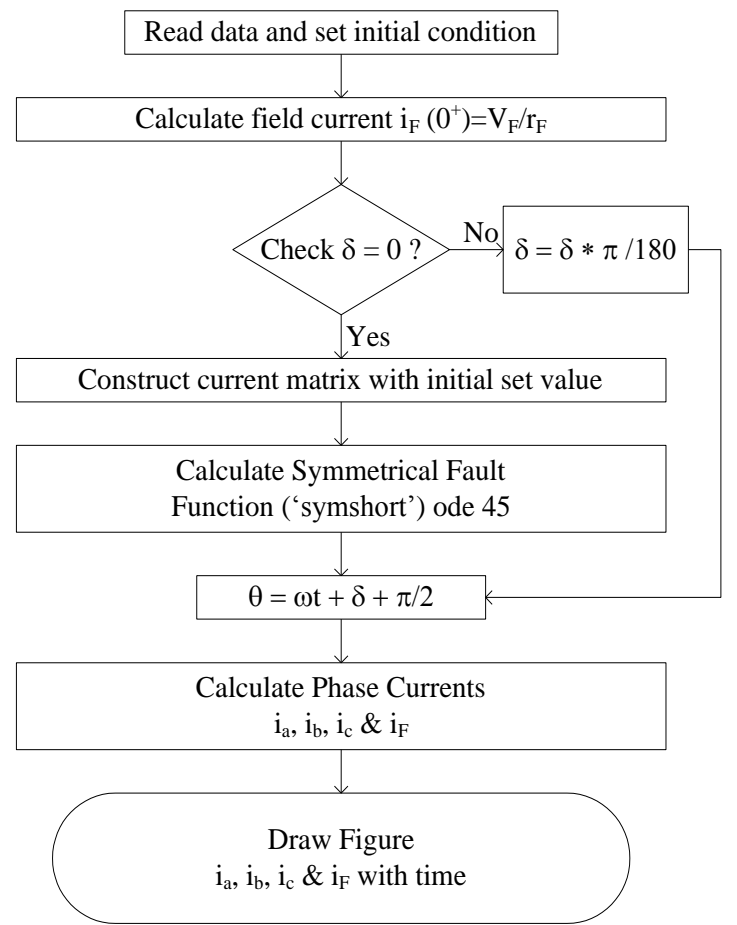

Figure 2. Flow Diagram for Symmetrical Three-Phase Short-Circuit

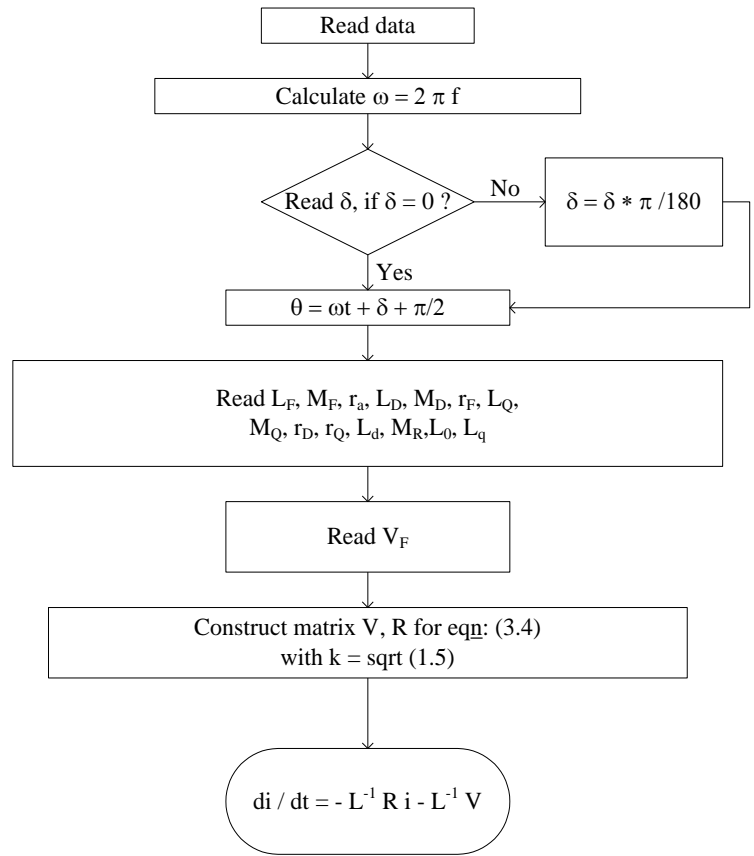

Figure 3. Flow Diagram of function "symshort" for Symmetrical Three-Phase Short-Circuit

\section{BALANCED THREE-PHASE SHORT CIRCUIT WAVEFORM}

If $\theta$ is the angle by which rotor direct axis is ahead of the magnetic axis of phase a, then 
$\theta=\omega \mathrm{t}+\delta+\pi / 2$ (shown in equation 1$)$

By changing $\delta$ as $0^{\circ}, 30^{\circ}, 60^{\circ}$ and $90^{\circ}$, the angle $\theta$ will be changed. Changing of angle $\theta$ will affect on phase current $i_{a}, i_{b}$ and $i_{c}$ as shown in equation (11).

In three phase symmetrical system, the phase angle between $i_{a}, i_{b}$ and $i_{c}$ are $120^{\circ}$ apart each other. If we let $i_{a}$ in $x$-axis at positive side, $i_{b}$ will be $60^{\circ}$ leading and $i_{c}$ will be $60^{\circ}$ lagging. The simulation results are as shown in Figure 4, Figure 5, Figure 6 and Figure 7 if we changed $\delta=0^{\circ}, 30^{\circ}, 60^{\circ}$ and $90^{\circ}$ alternatively. According to the simulation results, the results of Figure 4(a), Figure 4(b) and Figure 7(c) are the same in magnitude and different in phase angle. Next, the result of Figure 4(c), Figure 7(a) and Figure 7(b) are the same in magnitude and different in phase angle. Then, the results of Figure 5(a), Figure 5(b) and Figure 6(c) are the same in magnitude and different in phase angle. Finally, the results of Figure 5(c), Figure 6(a) and Figure 6(b) are the same in magnitude and different in phase angle. The simulation results of $i_{F}$ is the same in all Figure 4(d), Figure 5(d), Figure 6(d) and Figure 7(d).

Neglecting of all winding resistances will result in considerable numerical simplification, at a very convenient in lost accuracy.

$$
\begin{aligned}
& \mathrm{i}_{\mathrm{a}}\left(0^{+}\right)=\mathrm{i}_{\mathrm{b}}\left(0^{+}\right)=\mathrm{i}_{\mathrm{c}}\left(0^{+}\right)=0 \\
& \mathrm{i}_{0}\left(0^{+}\right)=\mathrm{i}_{\mathrm{d}}\left(0^{+}\right)=\mathrm{i}_{\mathrm{q}}\left(0^{+}\right)=0
\end{aligned}
$$

The initial value of the field current is

$\mathrm{i}_{\mathrm{F}}\left(0^{+}\right)=\frac{\mathrm{V}_{\mathrm{F}}}{\mathrm{r}_{\mathrm{F}}}$

For balanced three-phase short circuit at the terminals of the machine

$\mathrm{v}_{\mathrm{a}}=\mathrm{v}_{\mathrm{b}}=\mathrm{v}_{\mathrm{c}}=0$

Since $\mathrm{i}_{0}=0$, the machine equation in the rotor reference frame following a three-phase short circuit becomes

$$
\begin{aligned}
{\left[\begin{array}{c}
\mathrm{v}_{\mathrm{d}} \\
-\mathrm{v}_{\mathrm{F}} \\
0 \\
\mathrm{v}_{\mathrm{q}} \\
0
\end{array}\right]=} & -\left[\begin{array}{ccccc}
\mathrm{r} & 0 & 0 & \omega \mathrm{L}_{\mathrm{q}} & \omega \mathrm{kM} \\
0 & \mathrm{r}_{\mathrm{F}} & 0 & 0 & 0 \\
0 & 0 & \mathrm{r}_{\mathrm{D}} & 0 & 0 \\
-\omega \mathrm{L}_{\mathrm{d}} & -\omega \mathrm{kM}_{\mathrm{F}} & -\omega \mathrm{kM}_{\mathrm{D}} & \mathrm{r} & 0 \\
0 & 0 & 0 & 0 & \mathrm{r}_{\mathrm{Q}}
\end{array}\right]\left[\begin{array}{c}
\mathrm{i}_{\mathrm{d}} \\
\mathrm{i}_{\mathrm{F}} \\
\mathrm{i}_{\mathrm{D}} \\
\mathrm{i}_{\mathrm{q}} \\
\mathrm{i}_{\mathrm{Q}}
\end{array}\right] \\
& -\left[\begin{array}{ccccc}
\mathrm{L}_{\mathrm{d}} & \mathrm{kM}_{\mathrm{F}} & \mathrm{kM}_{\mathrm{D}} & 0 & 0 \\
\mathrm{kM}_{\mathrm{F}} & \mathrm{L}_{\mathrm{F}} & \mathrm{M}_{\mathrm{R}} & 0 & 0 \\
\mathrm{kM}_{\mathrm{D}} & \mathrm{M}_{\mathrm{R}} & \mathrm{L}_{\mathrm{D}} & 0 & 0 \\
0 & 0 & 0 & \mathrm{~L}_{\mathrm{q}} & \mathrm{kM}_{\mathrm{Q}} \\
0 & 0 & 0 & \mathrm{kM}_{\mathrm{Q}} & \mathrm{L}_{\mathrm{Q}}
\end{array}\right] \mathrm{\frac { \textrm {d } } { \mathrm { dt } }}\left[\begin{array}{c}
\mathrm{i}_{\mathrm{d}} \\
\mathrm{i}_{\mathrm{F}} \\
\mathrm{i}_{\mathrm{D}} \\
\mathrm{i}_{\mathrm{q}} \\
\mathrm{i}_{\mathrm{Q}}
\end{array}\right]
\end{aligned}
$$

This equation is in the state-space form and can be written in compact form as

$$
\begin{aligned}
& v=-R i-L \frac{d}{d t} i \\
& \frac{d}{d t} i=-L^{-1} R i-L^{-1} v
\end{aligned}
$$

\subsection{Synchronous Machine Parameters}

A three-phase model, which uses direct physical parameters, is well suited for simulation on a computer. And it is not necessary to go through complex transformations. The analysis can easily be extended to take the speed variation into account by including the dynamic equations of the machine. In this paper, assuming the machine data are as follow:

A $500-\mathrm{MVA}, \quad 30-\mathrm{kV}, 50-\mathrm{Hz}$ synchronous generator is operating at no-load with a constant excitation voltage of $400 \mathrm{~V}$.
The generator parameters for all Problems are

$$
\begin{array}{lll}
L_{d}=0.0072 \mathrm{H} & L_{q}=0.0070 \mathrm{H} & L_{F}=2.500 \mathrm{H} \\
L_{D}=0.0068 \mathrm{H} & L_{Q}=0.0016 \mathrm{H} & M_{F}=0.100 \mathrm{H} \\
M_{D}=0.0054 \mathrm{H} & M_{Q}=0.0026 \mathrm{H} & M_{R}=0.125 \mathrm{H} \\
r=0.0020 \Omega & r_{F}=0.4000 \Omega & r_{D}=0.015 \Omega \\
r_{Q}=0.0150 \Omega & L_{0}=0.0010 \mathrm{H} &
\end{array}
$$

A three-phase short circuit occurs at the armature terminals. Use ode 45 to simulate equation (16), and obtain the transient waveforms for the current in each phase and the field current.

\subsubsection{Case Study 1}

Assume the short circuit is applied at the instant when the rotor direct axis is along the magnetic axis of phase a, i.e., $\delta=0$. Also, assume that the rotor speed remains constant at the synchronous value.

The dc field voltage is $V_{F}=400 \mathrm{~V}$. The derivatives of the state equation given by equation (18), together with the coefficient matrices in equation (16) are defined in a function file named symshort.m, which returns the state derivatives. The initial value of the field current is

$$
\mathrm{i}_{\mathrm{F}}\left(0^{+}\right)=\frac{\mathrm{V}_{\mathrm{F}}}{\mathrm{r}_{\mathrm{F}}}=\frac{400}{0.4}=1000 \mathrm{~A}
$$

and since the machine is initially on no-load.

$$
\mathrm{i}_{0}\left(0^{+}\right)=\mathrm{i}_{\mathrm{d}}\left(0^{+}\right)=\mathrm{i}_{\mathrm{q}}\left(0^{0}\right)=0
$$

The program file cs $2 . \mathrm{m}$ from appendix uses ode 45 to simulate the differential equations defined in symshort over the desired interval. The periodic nature of currents necessitates a very small step size for integration. The currents $i_{d}$ and $i_{q}$ are substituted in equation (11) and the phase currents are determined. The results of the simulations of $\mathrm{i}_{\mathrm{a}}, \mathrm{i}_{\mathrm{b}}, \mathrm{i}_{\mathrm{c}}$ and $\mathrm{i}_{\mathrm{F}}$ are shown in Figure 4

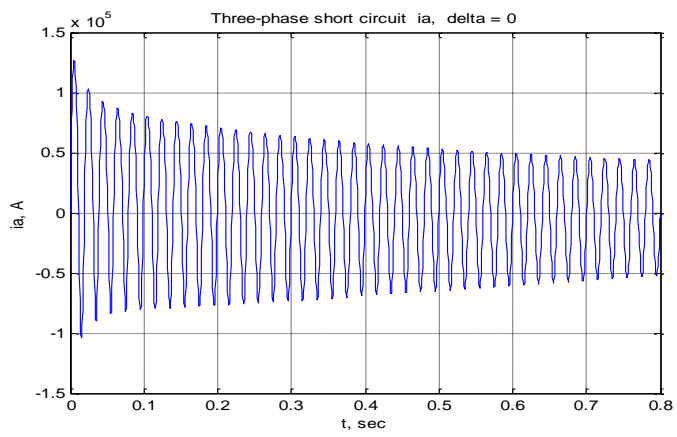

(a)

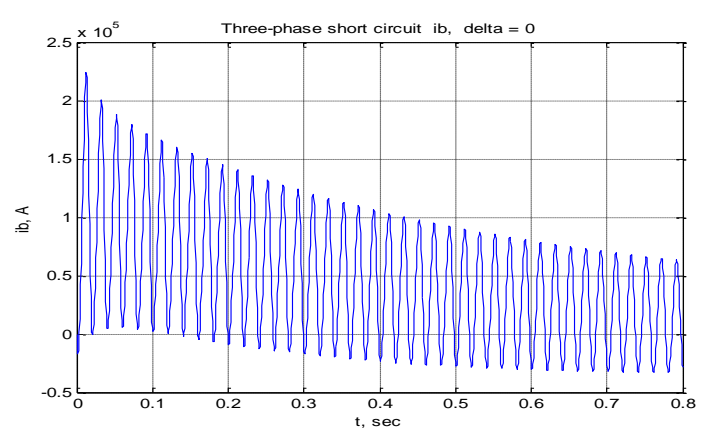

(b) 
International Journal of Science and Engineering Applications

Volume 3 Issue 5, 2014, ISSN-2319-7560 (Online)

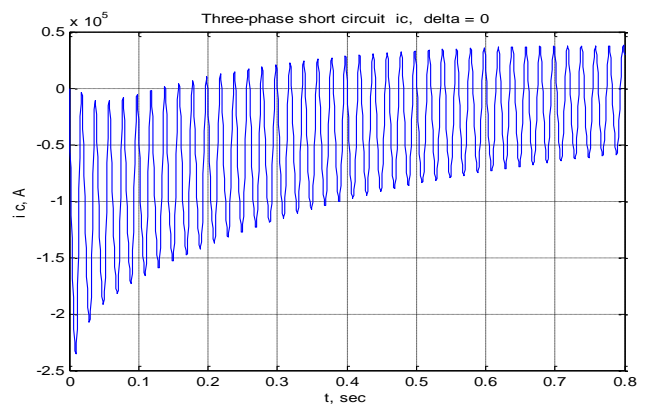

(c)

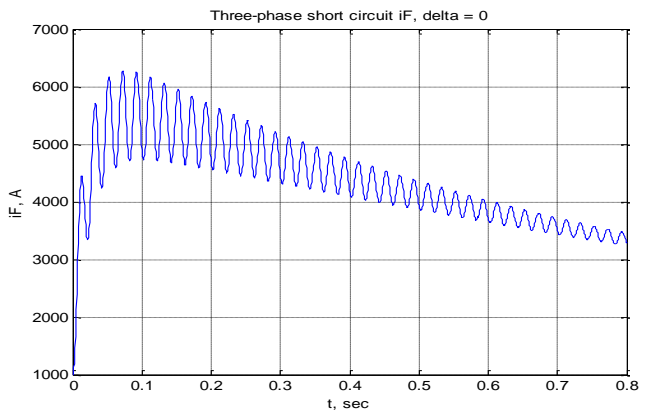

(d)

Figure 4. Balanced three-phase short-circuit current waveforms

\subsubsection{Case Study 2}

If the machine angle, $\delta$, is increased from $0^{\circ}$ to $30^{\circ}$, the waveforms of $i_{a}, i_{b}, i_{c}$ and $i_{F}$ are shown in Figure 5 .

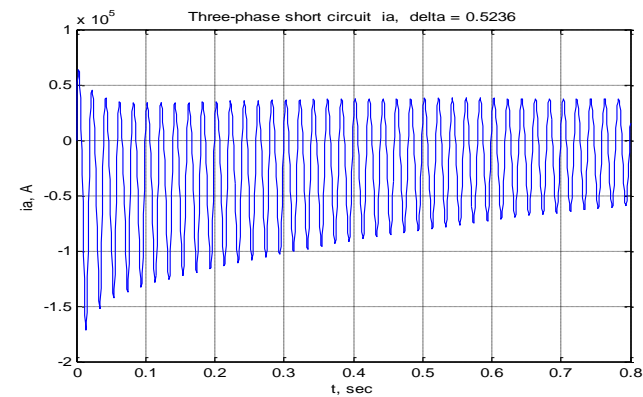

(a)

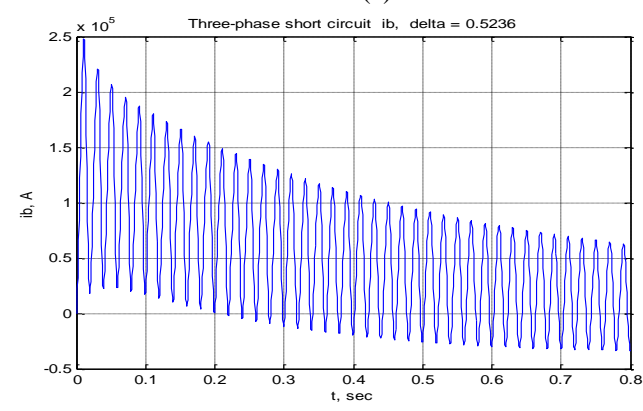

(b)

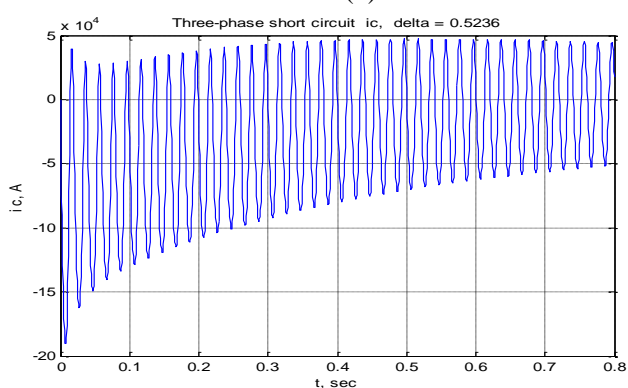

(c)

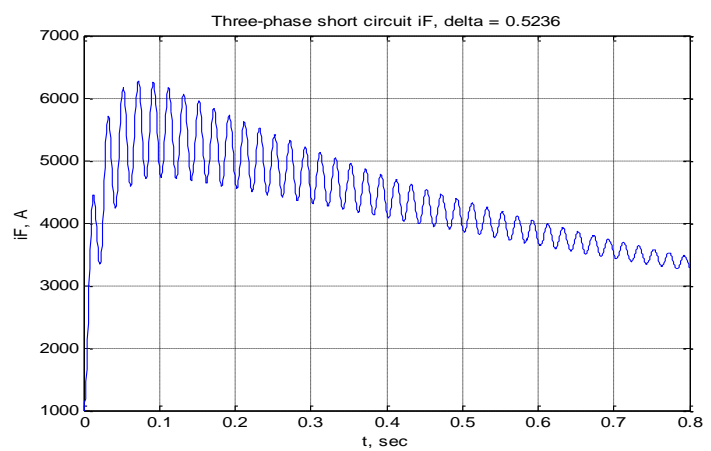

(d)

Figure 5. Balanced three-phase short-circuit current waveform at machine terminal $\left(30^{\circ}\right)$

This case study shows that rise of rotor angle is found to shift waveform position of armature currents. The settling time changes in small amount and $\mathrm{i}_{\mathrm{F}}$ is found to be unchanged.

\subsubsection{Case Study 3}

If the machine angle, $\delta$, is increased from $0^{\circ}$ to $60^{\circ}$ the waveforms of $i_{a}, i_{b}, i_{c}$ and $i_{F}$ are shown in Figure 6 .

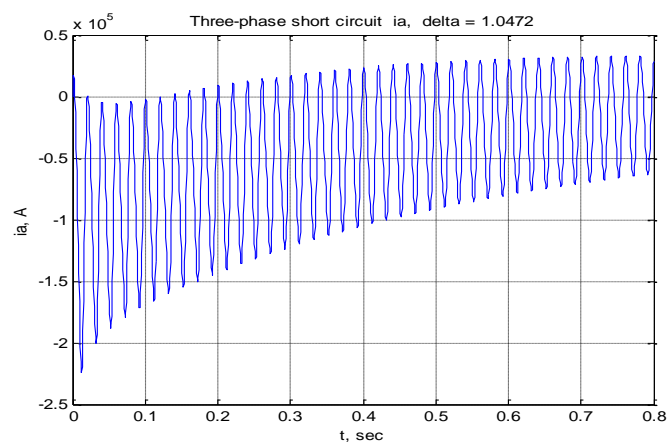

(a)

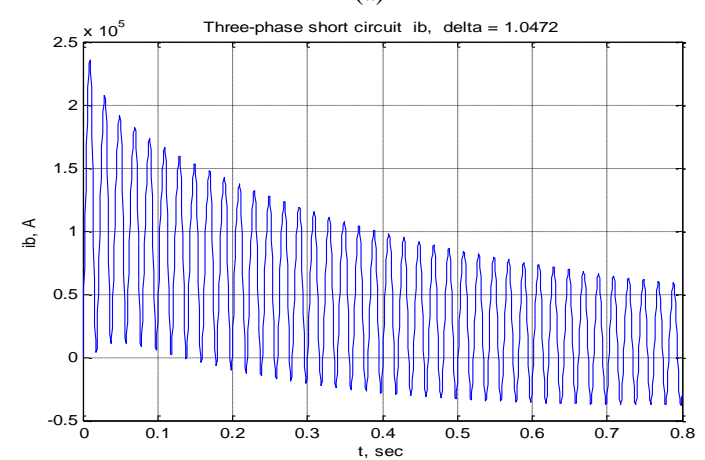

(b)

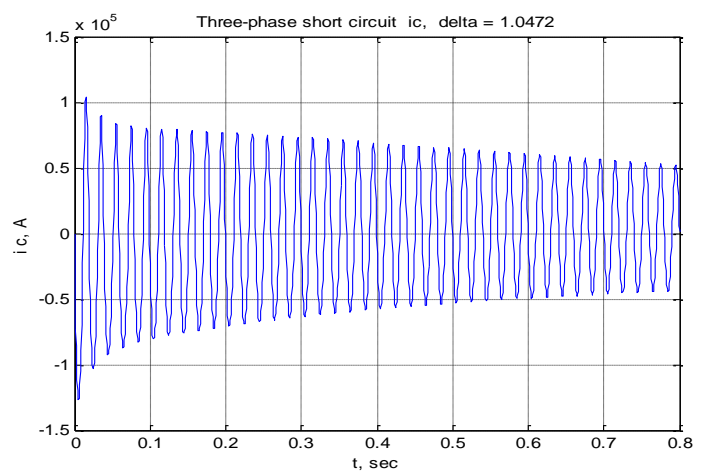

(c) 


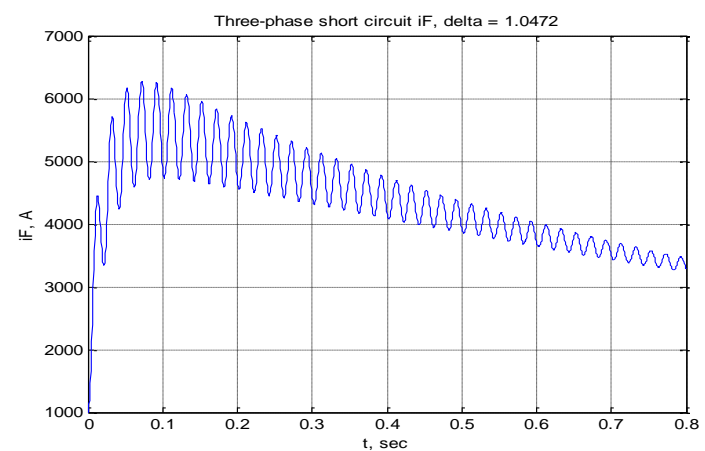

(d)

Figure 6. Balanced three-phase short-circuit current waveform at machine terminal $\left(60^{\circ}\right)$

\subsubsection{Case Study 4}

If the machine angle, $\delta$, is increased from $0^{\circ}$ to $90^{\circ}$ the waveforms of $i_{a}, i_{b}, i_{c}$ and $i_{F}$ are shown in Figure7.

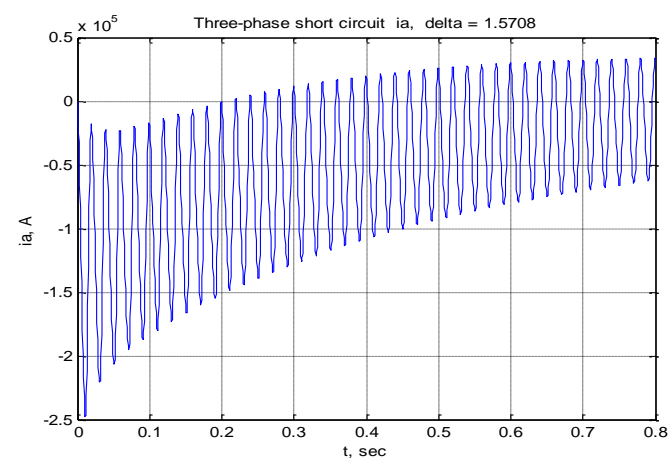

(a)

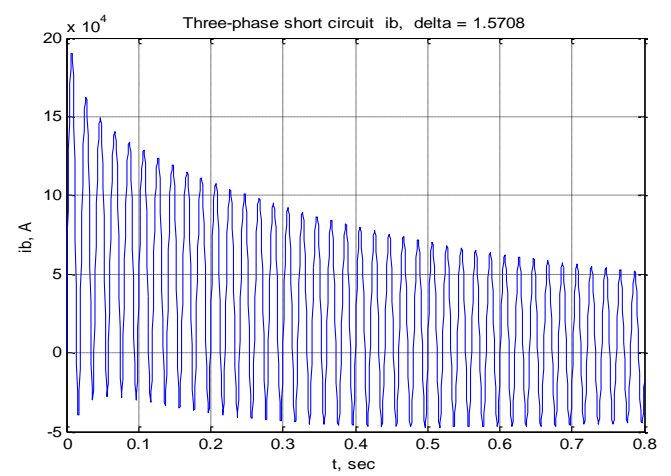

(b)

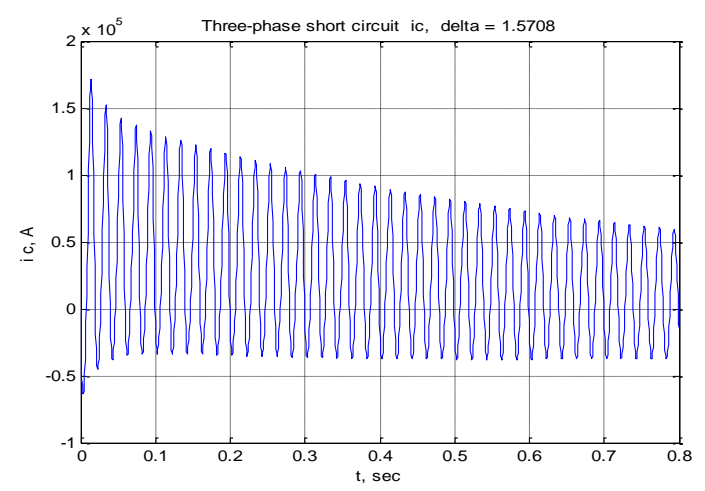

(c)

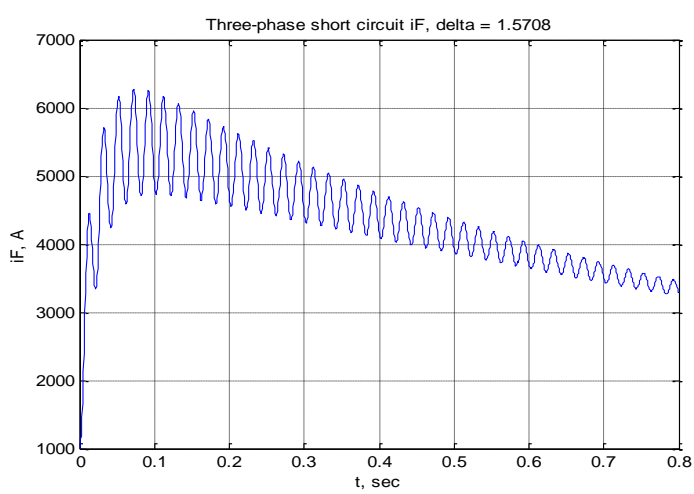

(d)

Figure 7. Balanced three-phase short-circuit current waveform at machine terminal $\left(90^{\circ}\right)$

The stated testings are found to give the design criteria and three-phase short circuit condition of a synchronous generator.

\section{CONCLUSION}

This paper has analyzed the conditions of three-phase short circuit on the terminals of the synchronous generator. A sudden three-phase short circuit is applied to the terminals of an unloaded generator and the waveform of the current is obtained by using the MATLAB program. Synchronous machines naturally operate at constant speed. But at transient condition, speed varies and thus the rotor angle $\delta$ changes causing instability. According to the simulation results, it can be seen that the fault current magnitude of phase $a, b$ and $c$ are remain the same while the rotor angle displacement varies. But the phase shift (or) the DC offset is occurred respectively with respect to the different rotor angles. Moreover, it can also be seen that the magnitude of field winding current at transient condition is significant but they are independent of rotor angle displacement. Furthermore, if the field voltage is increased, the magnitude of the fault current levels of $i_{a}, i_{b}, i_{c}$ and $i_{F}$ increase and when the field voltage is decreased, the magnitude of the fault current levels of $i_{a}, i_{b}, i_{c}$ and $i_{F}$ also decrease.

\section{ACKNOWLEDGMENT}

The author would like to express her gratitude to Dr. Khin Thuzar Soe, Associate Professor and Head of Electrical Power Engineering Department, Mandalay Technological University and Dr.Yan Aung Oo, Associate Professor, Department of Electrical Power Engineering, Mandalay Technological University for his encouragement and helpful suggestion and supervision. The author wishes to thanks all teachers. Thanks are also extended to her dear parent and friends for their support.

\section{REFERENCES}

[1] Adkins, General Theory of Electrical Machines, Chapman \& Hall, 1975

[2] Biran, A., and Breiner, M. 1996. MALAB for Engineer

[3] Hubert, C.I. 1991.Electric Machines

[4] I. R. Smith and S. Sriharan, Transient Performance of Induction Machines. Proc. IEE, 133, 1173, 1966.

[5] Kundur, P.1994. Power System Stability and Control 
International Journal of Science and Engineering Applications

Volume 3 Issue 5, 2014, ISSN-2319-7560 (Online)

[6] M. G. Say, Alternating Current Machine, Pitman Publishing Ltd, 4th Edition, 1976.

[7] P. J. Lawrence and J. M. Stevenson, Induction Machine Performance with a Variable Frequency Supply, Proc. IEE, 113, 1617, 1966.

[8] Saadat, H. 1999. Power System Analysis Singapore: McGraw-Hill Co.

[9] Elgerd, O.I. 1971. Electric Energy System Theory: An Introduction U.S.A.: McGraw-Hill Book Co. 